\title{
Examination of Optimum Construction Area for Appropriate Thickness in Polyurethane Waterproofing Construction
}

\author{
Yuji Hosshin $^{1}$, Saori Ishihara ${ }^{2}$ and Kyoji Tanaka ${ }^{3}$ \\ ${ }^{1}$ Haseko Corporation, 32-1 Shiba 2-chome, Minato-ku, Tokyo, Japan 105-8507, \\ Yuji_Hosshin@haseko.co.jp \\ ${ }^{2}$ Chiba Institute of Technology, 2-17-1 Tsudanuma Narashino-shi Chiba, Japan 275-0016, \\ saori.ishihara@it-chiba.ac.jp \\ ${ }^{3}$ Tokyo Institute of Technology, 9-2 Nihonbashi hisamatsutyo chuo-ku Tokyo, Japan 103-0005, \\ tanaka-kyoji@kme.biglobe.ne.jp
}

\begin{abstract}
Polyurethane waterproofing membranes are constructed at building sites by applying liquid material to substrate. The membrane thickness is related to the durability of the waterproof material, so quality control during construction is important. However, the membrane thickness is likely to be unstable because it is affected by various factors, such as the environment, substrate conditions, method of waterproofing material application, and construction skills. Therefore, a reduction in thickness variation is extremely important to secure the quality of the waterproofing membrane.

To examine which construction conditions can ensure a uniform and appropriate thickness, we examined the combination of allocation method of the suitable construction area and application tools as an example of process control during construction. The construction area width and length were important, and a comparatively uniform and appropriate thickness could be ensured, when construction was carried out over an area with a 1.4- $\mathrm{m}$ width and length of $5.15 \mathrm{~m}$ by using the trowel and squeegee.
\end{abstract}

Keywords: Waterproofing Membrane, Polyurethane, Thickness of Membrane, Construction Area, Application Tool.

\section{Introduction}

Waterproofing membranes that are generally used in Japan are a liquid material that is applied to a base in a construction site, and a waterproof layer is formed by its hardening. The most important quality control item is to ensure the appropriate membrane thickness, which is related directly to the performance and service life of the waterproof layer. However, the membrane thickness tends to become unequal, because it is affected by the construction environment, foundation conditions, material, application method, and skill. Standard Japanese specifications state that the thickness of the waterproof urethane coating membrane is confirmed by the quantity used per unit area. However, there is no more detailed description of the concrete construction method except for "In order to secure the thickness of membrane, the coating amount per set of waterproof material is divided." Therefore, in many cases, concrete construction is achieved by the judgment of the constructor, and as a result, waterproof layers do not always reach the prescribed membrane thickness.

In this study, waterproofing membrane formation during construction was studied, and the effect of area on the membrane thickness was examined as an example of the quality control technique. The waterproof layer construction must be carried out over an appropriate time, and this paper aims to show the optimum construction area by considering these. By using a 
concrete repair site floor and indoor laboratory, we carried out experiments by combining the partition shape and sprinkling method of the waterproof material and construction equipment as factors.

\section{Effect of Observation of Waterproofing Membrane Work and Construction Area on Membrane Thickness}

\subsection{Experimental Outline}

The experiment was carried out by using the roof of a multiple-dwelling house to observe the work content during waterproofing membrane construction and the effect of construction area on the membrane thickness. The plain field with a comparatively small gradient was selected as the waterproofing underlayer, and the area was made to be $14.0 \mathrm{~m}^{2}(4.0 \mathrm{~m} \times 3.5 \mathrm{~m})$ by converting $27 \mathrm{~kg}$ of waterproofing material in one set into a target membrane thickness of 1.5 $\mathrm{mm}$ for one layer. As shown in Figure 1, two areas were prepared: area A in which the area line was indicated clearly, and area B in which a mark was provided at each of four corners. The waterproof material used was a two-component hand-kneaded type for flat field based on the Japanese Industrial Standard.
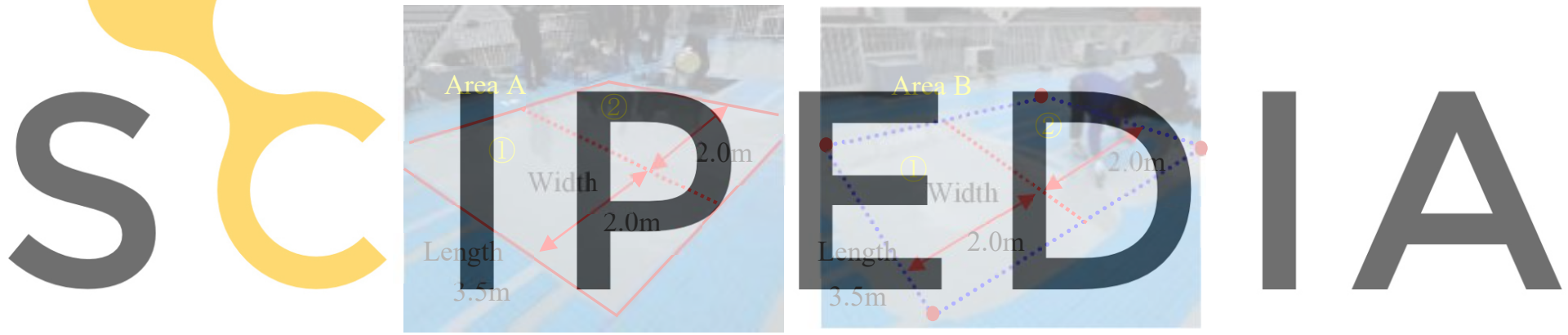

Register for free at https//yumw.scipedia.comytotdowntoadithetversion without the watermark

\subsection{Experimental Viethods}

The construction procedure was as follows. A ventilation buffer sheet was attached to the entire roof. Then, three rows of 50-mm-wide aluminum tape were installed at $1.0-\mathrm{m}$ intervals on the base surface because the membrane thickness is measured by a nondestructive inspection method (eddy current-type thickness membrane meter). The abovementioned area was prepared, and the waterproof layer was constructed with a target membrane thickness of $1.5 \mathrm{~mm}$. The constructor was a technician with more than 20 years of experience, and a trowel was used as the construction application tool. The outside air temperature was $12^{\circ} \mathrm{C}$ and the humidity was $45 \%$.

\subsection{Work Observation and Thickness of Membrane-Measurement Methods}

During the experiment, moving image photography was carried out from the work start to the end, and the work content of the constructor was observed. After confirmation of the hardening of the waterproof layer on the following day, the membrane thickness was measured by using an eddy current-type thickness membrane meter. The measurement points were placed at 45 locations on the aluminum tape in each construction area. 


\subsection{Work Contents of Contractor}

The waterproofing membrane was constructed as follows. The constructor divided the $4.0-\mathrm{m}$ wide $\times 3.5-\mathrm{m}$ long area into a $2.0-\mathrm{m}$ width in which work was possible. A two-component waterproof material was kneaded with a main agent and a hardener in the field. The kneaded waterproof material was halved $(13.5 \mathrm{~kg})$ to fit the divided width of $2.0 \mathrm{~m} \times 3.5 \mathrm{~m}$ length and poured using a container. The waterproofing material that was poured in the construction area was spread right and left by using a trowel. The other half of the plots was subjected to similar work. Observation indicated that the waterproofing membrane construction is composed of work where material was poured on the base and work where material was spread. The construction area in the field was divided by the width in which the spreading work was easy, and the amount of waterproof material poured was calculated in proportion.

\subsection{Effect of Construction Area}

The measured membrane thickness is shown in Figure 2 and it varied across both construction areas. In construction area $\mathrm{A}$ in which the area was strengthened, the average membrane thickness was $1.2 \mathrm{~mm}$. In construction area B, which was constructed without much attention given to the area, the waterproof material protruded from the area. Therefore, the coating quantity in the area was insufficient compared with construction area $\mathrm{A}$, and the average membrane thickness decreased to $0.9 \mathrm{~mm}$.

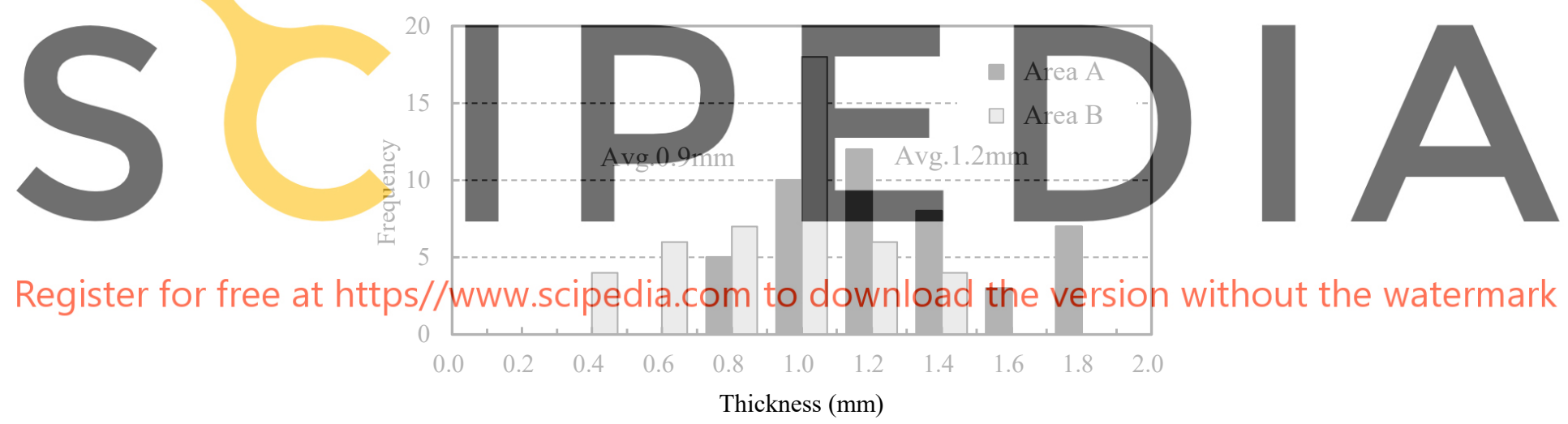

Figure 2. Measured thickness of areas A and B.

\section{Effect of Pouring Waterproofing Membrane Material on Variation of Membrane Thickness}

\subsection{Experimental Outline}

The work observation indicated that it is necessary for the constructor to pour waterproof material evenly from the container to the prescribed area, and to spread it uniformly by using the construction tool. The waterproofing membrane thickness, "Area Length" appears to be related to the pouring of the waterproof material, and the "Area Width" appears to be related to the work of pushing and spreading. Therefore, the experiment was carried out by using these as variables. A concrete floor ( $<3 / 1000$ accuracy) in an indoor laboratory was used as a base.

In the confirmation experiment of the preceding section, the partition width was divided into 
$2.0 \mathrm{~m}$ to facilitate the spreading. This experiment was carried out at three section-length levels of $9.0 \mathrm{~m}$ ( $0.8 \mathrm{~m}$ wide), $5.15 \mathrm{~m}$ (1.4 $\mathrm{m}$ wide), and $3.6 \mathrm{~m}$ ( $2.0 \mathrm{~m}$ wide), with a $7.2 \mathrm{~m}^{2}$ construction area. To omit mixing in the field, the waterproof material of one component type for a flat field based on the Japanese Industrial Standard was used.

\subsection{Experimental Methods}

The construction procedure was as follows. First, a polyethylene film sheet was laid on the working surface because the waterproof material after curing was peeled from the base and the mass was measured. The division was carried out and waterproof material $(14.0 \mathrm{~kg})$ that was suitable for a target film thickness of $1.5 \mathrm{~mm}$ was poured linearly in the center of the division width by using a pail can as shown in Figure 3. These operations were carried out in an environment at a room temperature of $\sim 23{ }^{\circ} \mathrm{C}$ and a $60 \%$ relative humidity by technicians with more than 20 years of experience. After confirming the hardening of the waterproof layers the following day, the spread waterproof material was cut into 10 pieces and its mass was measured.
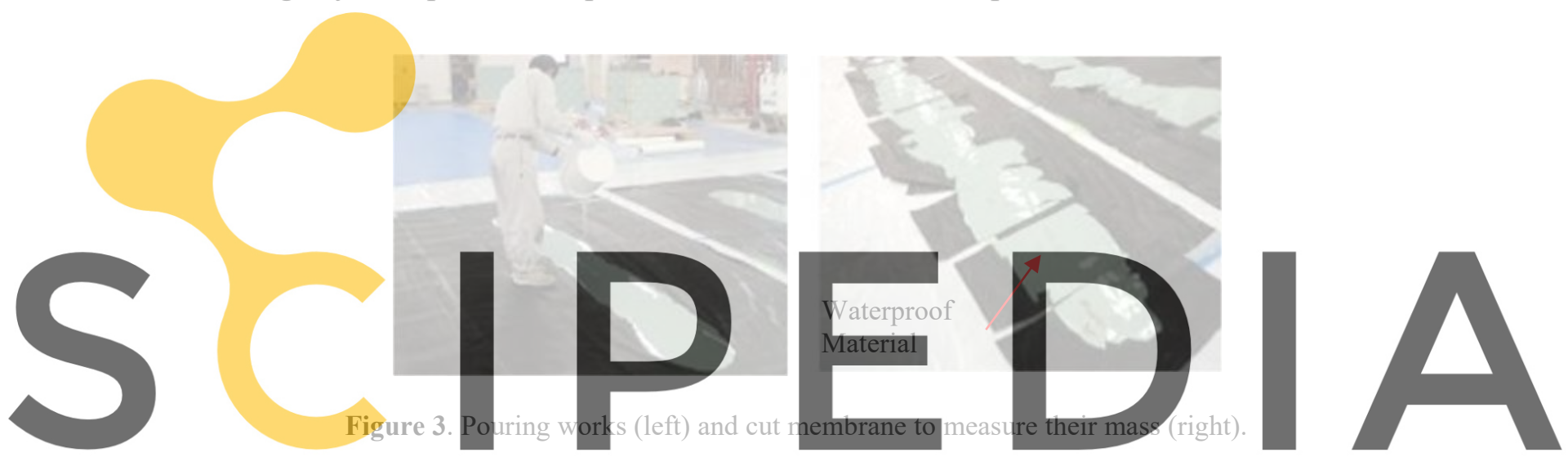

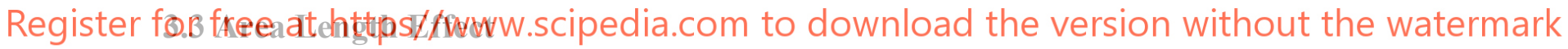

When the pouring work was observed, the waterproofing material appeared to flow out uniformly from the container. However, the variation after curing was large, wide, and narrow portions were intermingled. The mass standard deviation per unit length is shown in Figure 4.

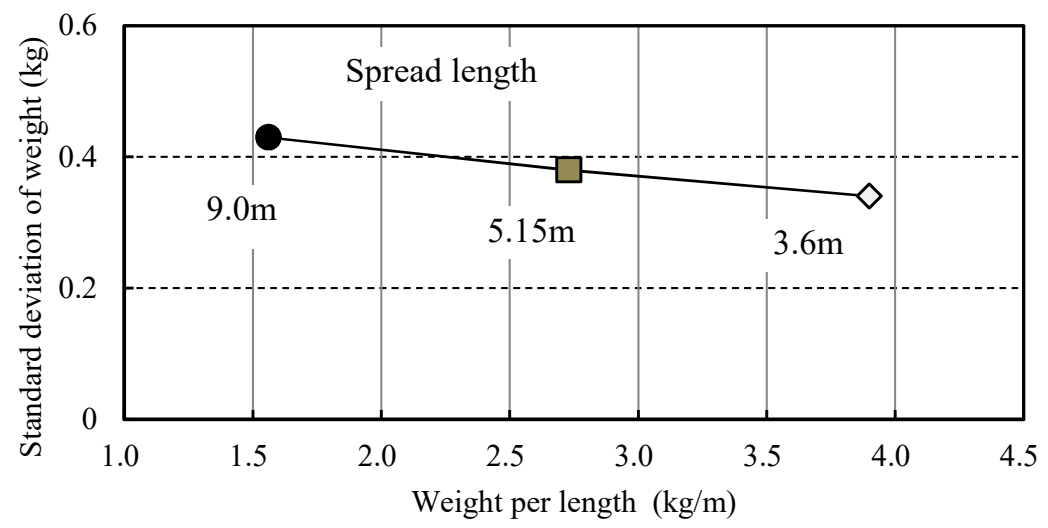

Figure 4. Relationship between material masses in three areas and their standard deviations Polyurethane material and standard deviation of mass. 
based on the measured mass of the waterproof material. The standard deviation of the area length of $9.0 \mathrm{~m}$ was $0.43 \mathrm{~kg}$, that of $5.15 \mathrm{~m}$ was $0.38 \mathrm{~kg}$, and that of $3.6 \mathrm{~m}$ was $0.34 \mathrm{~kg}$. This information shows that the material tended to be poured unevenly, when the length from which the waterproof material was poured was lengthened.

\section{Effect of Spreading Urethane Coating Waterproof Material on Membrane Thickness}

\subsection{Experimental Outline}

To confirm the effect of the "Area Width" on the film thickness, the experiment was carried out with the same concrete base and construction area as used previously. The division width was made to be three levels of a width of: $1.4 \mathrm{~m}(5.1 \mathrm{~m} \mathrm{long})$, which allows for a natural trowel movement to the left and right; a narrower $0.8 \mathrm{~m}$ (9.0 m long); and a wider $2.0 \mathrm{~m}$ (3.6 m long).

As shown in Figure 5, the construction tool was a trowel, which was a standard construction tool, and a polyethylene patterned squeegee with a $5-\mathrm{mm}$ groove depth and a $600-\mathrm{mm}$ width. The target waterproof layer membrane thickness was $1.5 \mathrm{~mm}$ for the first layer and $1.5 \mathrm{~mm}$ for the second layer, which totaled $3.0 \mathrm{~mm}$. The waterproofing material was used in a commercial onecomponent-type flat field, and the regulated quantity was measured for each construction area.

These tasks were performed by technicians with more than 20 years of experience in an environment of $\sim 23{ }^{\circ} \mathrm{C}$ and a $60 \%$ relative humidity.

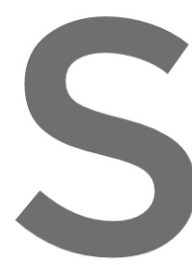
4.2 Experimental Methods
The construction proded
with aluminum alloy thin film w
thickness was measured
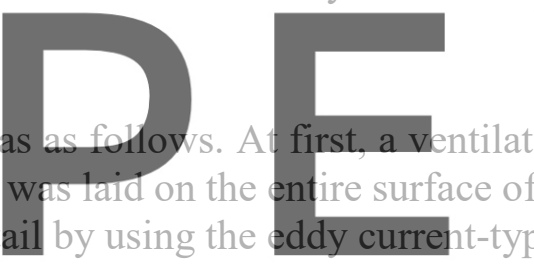
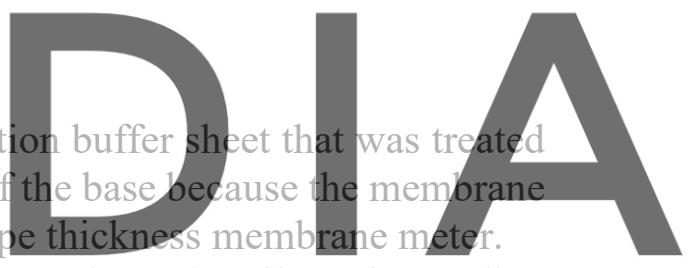

The area was divided by the above-mentioned area width. To evaluate the effect of spreading

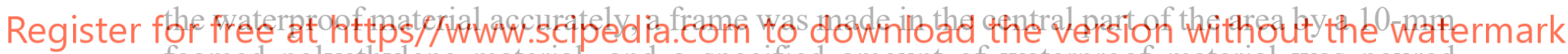
foamed polyethylene material, and a specified amount of waterproof material was poured uniformly into the frame. The waterpro of material was spread with each construction tool. After confirming the hardening of the waterproof layer, the thickness of the first layer was measured.

The second layer was constructed by the same construction method, and the total membrane thickness was measured on the next day. The membrane thickness was measured at 105 positions
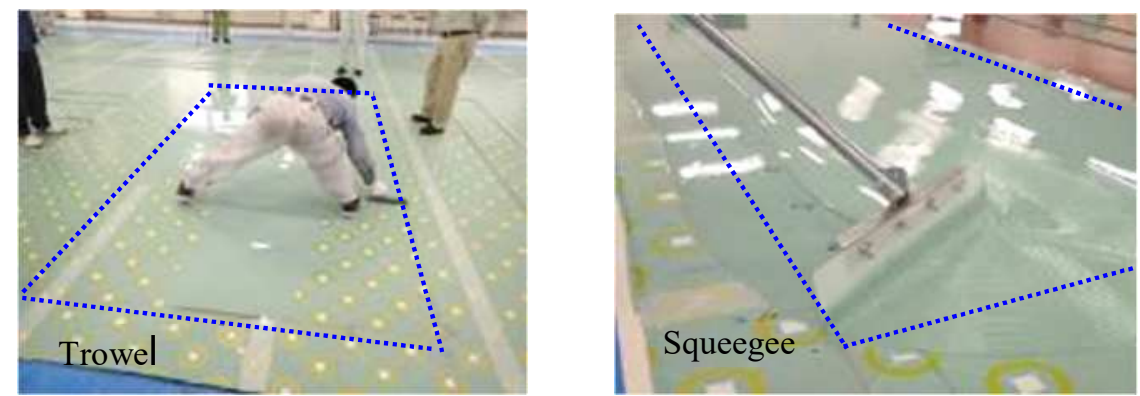

Figure 5. Spreading work using a trowel (left) and using a squeegee (right). 
from the center of the partition width at 0.3 -m intervals on the left and right sides, respectively. The time required from the start to the end of the spreading work was also measured.

\subsection{Effects of Area Width and Application Tools on Membrane Thickness}

The relationship between the mean membrane thickness and the standard deviation is shown in Figure 6. The membrane thickness distribution from the spreading work tends to be larger in the second layer. The average membrane thickness from the trowel was $1.3-1.4 \mathrm{~mm}$ in the first layer and $2.8 \mathrm{~mm}$ in the second layer. The value tended to be close to the target membrane thickness, which indicates that the target membrane thickness is approached regardless of the partition shape when the specified amount of waterproofing material is sprayed by specifying the partition. The membrane thickness distribution increased as the area width increased and was $1.1-1.9 \mathrm{~mm}$ in the first layer and $1.9-3.5 \mathrm{~mm}$ in the second layer. This occurs because, when the area widens, the distance required to move the trowel to the right and left increases, and it becomes difficult to push and expand the waterproof material uniformly. The average squeegee membrane thickness was $1.3 \mathrm{~mm}$ in the first layer, it became $2.7-2.5 \mathrm{~mm}$ in the second layer, and it decreased with an increase in area width.

When the construction area was observed, the waterproof material stuck out from the area by back and forth application by the tool. Therefore, the coating quantity in the construction area is believed to be insufficient, and the film thickness was affected. The membrane thickness dispersion decreased as the area width increased. The membrane thickness of the first layer was

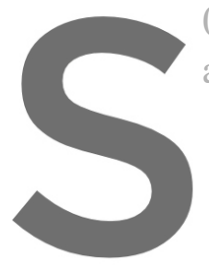
$0.9 \mathrm{~mm}$ and that of achieved with the trowe
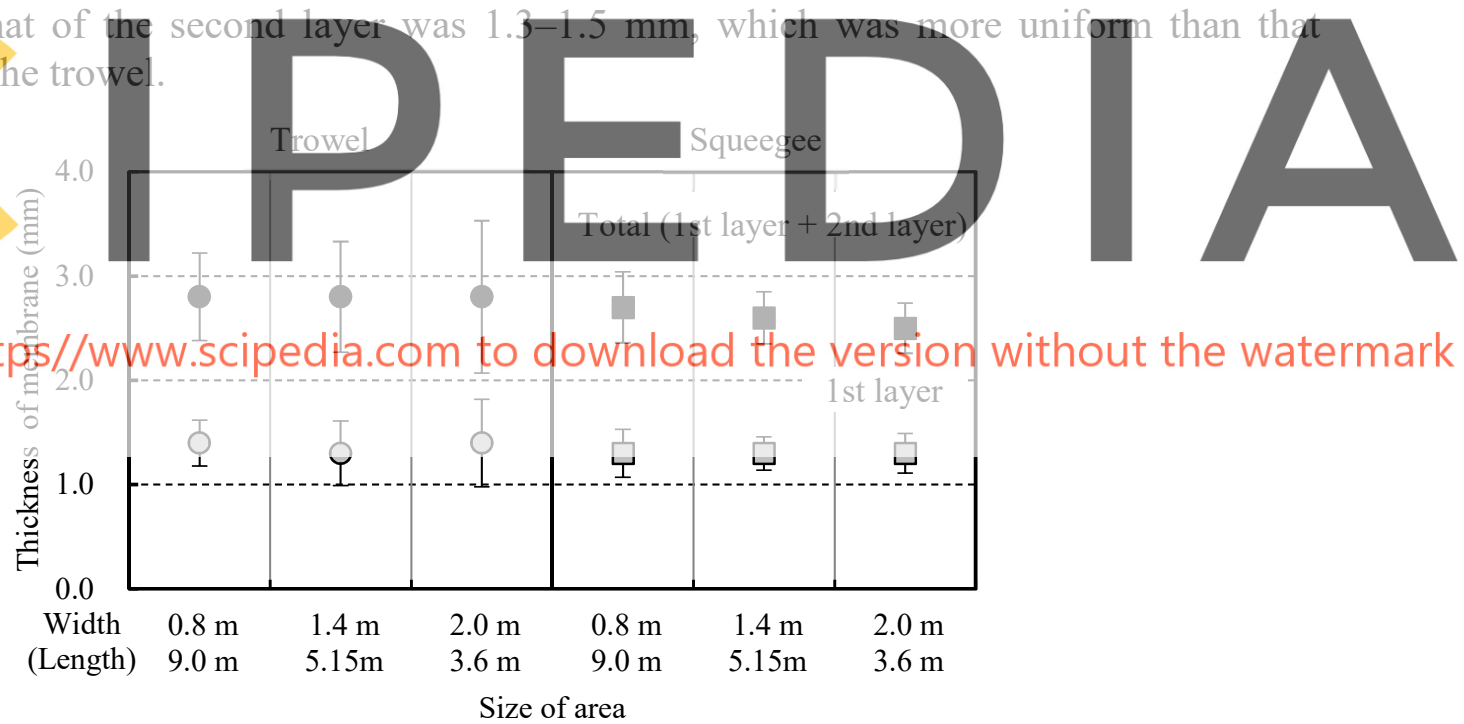

Figure 6. Average thickness of membrane and standard deviation of three.

\subsection{Effect of Area Width and Application Tools on Work Time}

Figure 7 shows the relationship between the shape of the construction areas and the work time for each construction application tool. The work time for the trowel decreased as the area width increased, especially in the second layer. For the squeegee, the work time lengthened as the area widened. This tendency is opposite to that for the trowel because a large amount of waterproofing materials can be pushed out at one time when the area width increased. The squeegee is efficient when the area length is long because it requires application tools to carry 
out the spreading work while pulling in the advancing direction. However, it is necessary to turn the application tools back and forth at a considerable frequency, when the area width widens like this experiment, and these appear to affect the work time.

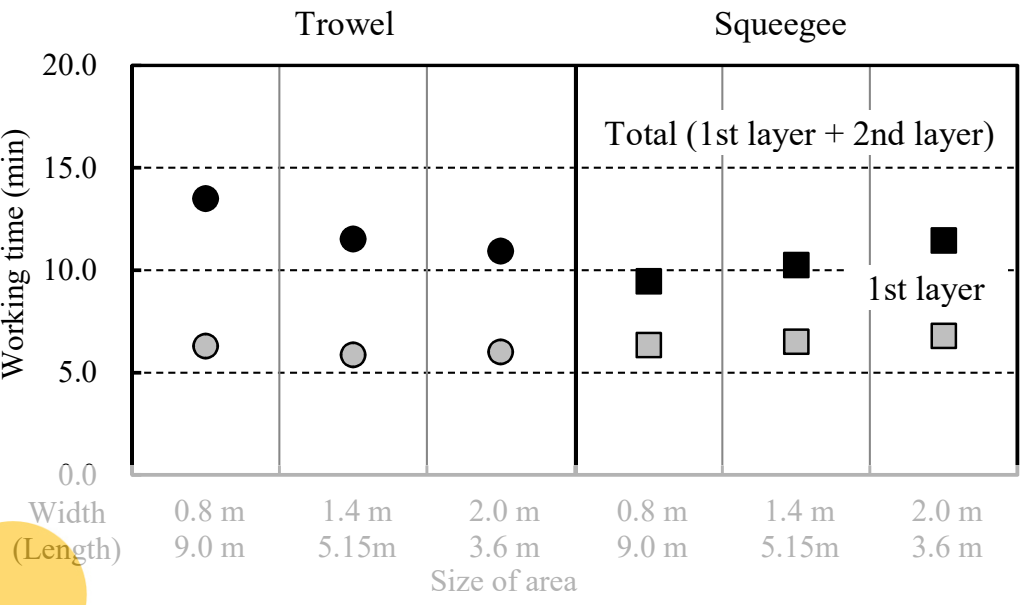

Figure 7. Working time in spreading work of three areas.

\subsection{Consideration of Optimal Construction Area from the Viewpoint of Securing Membrane Thickness}

The standard deviation of the membrane thiclmess for the trowel and squeegeg a
pouring and spreading work are shown in Figure 8. To ensure a stable nenbrand th
area with a wide width and a short length should be used in the pouring work. On
hand, the spreading work differs depending on the application tools and a narrow
desirable for the trowel. In a squeegee, the standard deviation tends to decrease as th

increases and the area 10

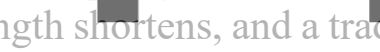

to be an effective application tool when the application quantity is easy to control compared

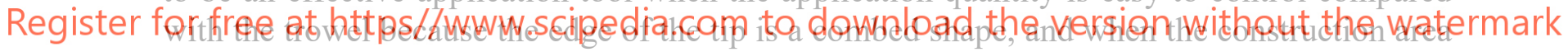

is wide. The work time is reduced, and the productivity is improved when the area width increases. However, a reciprocal relationship exists with the quality, and the membrane thickness

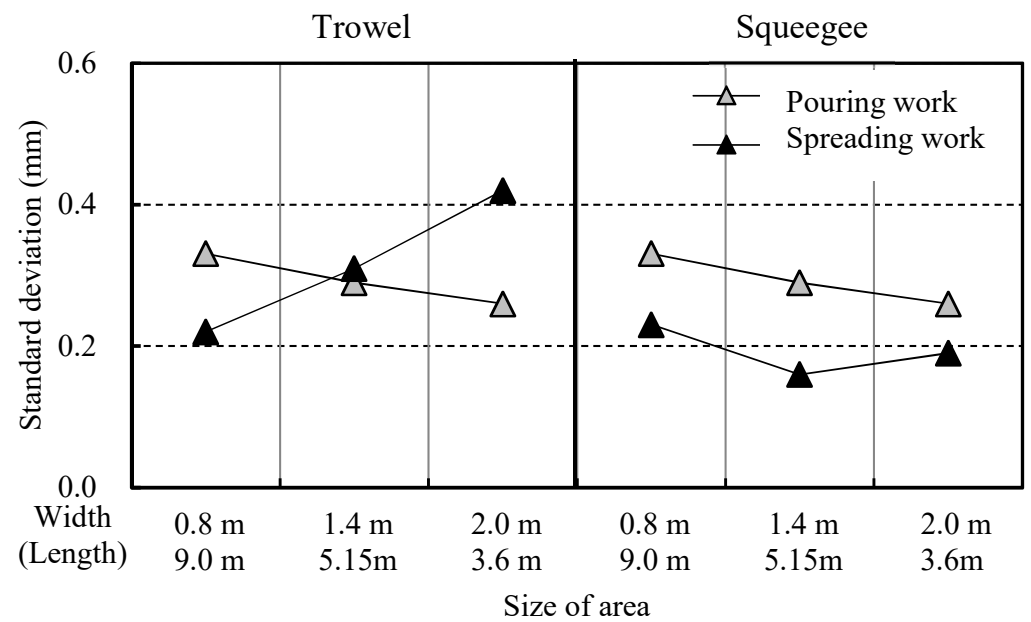

Figure 8. Standard deviation of membrane in pouring and spreading work. 
distribution increases, when the time is shortened excessively. The area and cure time of materials at the construction area and the work quantity and productivity must be considered and judged synthetically.

Although this experiment was a prerequisite construction area of $7.2 \mathrm{~m}^{2}$, it appeared to be a well-balanced construction area where the width of $1.4 \mathrm{~m}$ and the length of $5.15 \mathrm{~m}$ made it easy to prepare a suitable membrane thickness, when the time required for both application tools was considered.

\section{Conclusion}

We obtained the following conclusions from this study.

- To secure the waterproofing membrane thickness, a clarification of the construction area and the area shape are important in addition to the management of the application amount.

- During the waterproof material pour, the dispersion is smaller in the shorter area length. The length of the pouring waterproofing material increases and tends to be scattered unevenly.

- The area width of the spreading work differs according to the construction application tools. The membrane thickness distribution tended to be small; the partition width was narrow for the trowel and was widened with the squeegee.

The work time differed significantly according to the construction application tool. The work time decreased when the area width widened with the trowel and became narrower
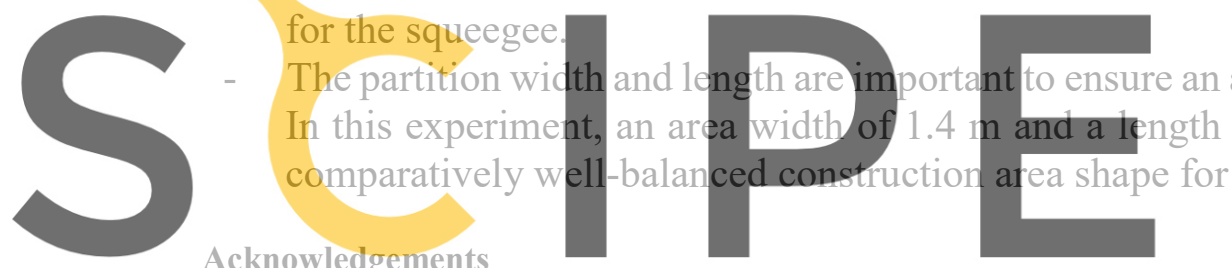

Acknowledgements
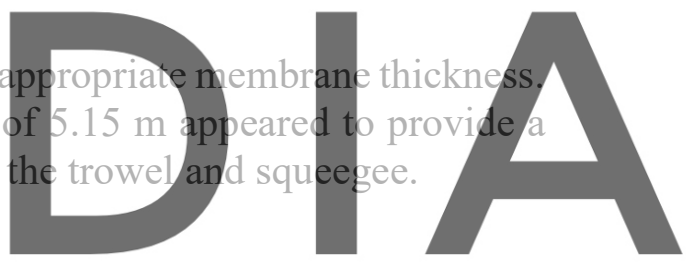

This study was conducted as part of.the activities of the Building, Waterproofing Safety and Quality Council,

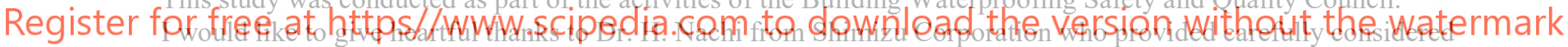
feedback and valuable comments.

\section{ORCID}

Yuji Hosshin: https://orcid.org/0000-0001-9591-2464

\section{References}

Hiroshi Nachi, Yuji Hosshin, Yoshiaki Takemoto, Saori Ishihara, Hikaru Watanabe, Kenji Kumagai, Yumiko Nakajima and Kyoji Tanaka (2018). Quality Control of Polyurethane Waterproofing Membranes usingthe Process Management Methods (in Japanese), AIJ Journal of Technology and Design, Vol. 24, No. 56, 23-27.

Japan Architectural Institute (2014). Standard construction specifications for construction work and commentary, JASS8 Waterproof construction.

Keiichi Nara, Saori Ishihara, Hayashi Kouichi, Nishimura Takeshi, Tanaka Hideo, Tsuruta Yutaka, and Kyoji Tanaka (2013). Effect of Dilution of Material and Application Tool on Thickness of Fluid-Applied Polyurethane Membrane (in Japanese), AIJ Journal of Technology and Design,Vol. 19, No. 42, 397-402.

Public Buildings Association (2016). Public Building Construction Standard Specification (Construction Work). Saori Ishihara and Kyoji Tanaka (2014). Effects of Polyurethane Dilution and Choice of Application Tool on the Workability and Thickness of Fluid-Applied Polyurethane Membranes (in Germany),Proceedings of International Conference on Building Envelope Systems and Technologies. 